\title{
EFFECT OF ANTENATAL CARE ON PREGNANCY INDUCED HYPERTENSION
}

Sunita Mishra, Rajesh Kumar Jha, Ratna Thakur, Abhishek Singhai

\author{
1. Post Graduate Student, Department of Obstetrics \& Gynaecology, Sri Aurobindo Medical College, Indore. \\ 2. Professor \& Head, Department of Medicine, Sri Aurobindo Medical College, Indore. \\ 3. Professor \& Head, Department of Obstetrics \& Gynaecology, Sri Aurobindo Medical College, Indore. \\ 4. Assistant Professor, Department of Medicine, Sri Aurobin do Medical College, Indore.
}

\section{CORRESPONDING AUTHOR}

Sunita Mishra,

Postgraduate Student,

Department of Obstetrics \& Gynaecology,

Sri Aurobindo Medical College, Indore

E-mail: dr_sunitamishra_16@yahoo.co.in,

Ph: 00919893361434

ABSTRACT: CONTEXT: Pregnancy induced hypertension (PIH) accounts for almost 10 to 15\% of antenatal cases. As per WHO "In developing countries like India there is $40 \%$ increase in the incidence of PIH in recent years." AIMS: To evaluate the effect of good antenatal care on incidence \& outcome of pregnancy induced hypertension in booked versus unbooked cases.

Settings and Design: This was an open labeled and comparative study. METHODS AND MATERIAL: This study was conducted on 340 patients admitted in the Department of Obstetrics and Gynaecology at Sri Aurobindo Medical College, Indore over a period of 6 months.

Results: Out of 340 antenatal cases studied, 44 cases were found to be suffering from pregnancy induced hypertension. Incidence came out to be $13 \%$. Out of $13 \%, 8.53 \%$ were primigravida and $4.4 \%$ were multigravida. Out of total PIH cases, $36.15 \%$ cases were booked cases whereas 63.30\% cases were unbooked. CONCLUSIONS: Pregnancy induced hypertension is not a totally preventable disease but maternal and foetal Complication due to PIH can be halted at mild stage by quality antenatal care with good outcome.

KEY-WORDS: Antenatal care, Pregnancy induced hypertension, Incidence, Outcome

INTRODUCTION: Pregnancy induced hypertension (PIH) accounts for almost 10 to $15 \%$ of antenatal cases.(1) As per WHO, in developing countries like India there is $40 \%$ increase in the incidence of PIH(2). Incidence of PIH in hospital practice varies widely. Imperfect documentation and lack of uniformity in the diagnostic criteria are responsible factors in variation of statistics. In developing Countries incidence is expected to be higher. Comparative low figures in hospital statistic are due to inclusion of only severe degree of the Syndrome, the minor ones being ignored.

MATERIALS AND METHODS: The patients attending antenatal clinics and those admitted in labour room were selected as cases irrespective of age and parity. On a specially designed proforma for this study, the patient's particulars including detailed obstetric examinations and lab findings were recorded.

ESSENTIAL CRITERIA: PIH of early onset (B.P >140/90 mm Hg after 20 weeks of gestation but before 32 weeks) associated with proteinuria and edema. 


\section{EXCLUSION CRITERIA:-}

(i)Essential Hypertension which is suggested by-

a. History of documentation of Hypertension in Prepregnant state

b. Hypertension present in before 20 weeks of gestation and beyond 3 months postpartum period.

(ii) Renal hypertension suggested by-

a. Renal Parenchymal disease usually chronic renal failure which can be documented only by ultrasonography of abdomen /renal biopsy.

b. Renovascular - clinically can be documented by finding renal artery bruit.

INVESTIGATIONS: Blood was collected in a sterile disposable Syringe. Collected blood immediately transferred to plain glass test tube for renal function test, liver function test, and complete haemogram. All Investigations including - SGOT, SGPT, Serum creatinine, Serum uric acid, Blood urea, Platelet count, HB, Total leucocyte count, urine examination(3) were done using standard methods ${ }^{(4)}$.

RESULTS: PIH detected in 44 cases out of 340 cases attending antenatal clinic. Among 44 cases, 16 cases were booked cases and 28 were unbooked cases. Incidence came out to be $13 \%$. Out of $13 \%, 8.53 \%$ were primigravida and $4.4 \%$ were multigravida. Out of total PIH cases, $36.15 \%$ cases were booked cases whereas $63.30 \%$ cases were unbooked.

Only 2 booked cases suffered from maternal morbidity that too of lower grade and 5 unbooked cases developed maternal morbidity. Only single maternal mortality noted in unbooked cases group.

DISTRIBUTION OF PIH CASES ACCORDING TO FOETAL OUTCOME: All booked case delivered healthy baby whereas babies of unbooked cases suffered from intrauterine growth retardation and intrauterine death.

DISCUSSION: Epidemiological studies report that hypertension complicates $10 \%$ of all pregnancies. ${ }^{(5)}$ In USA 7-10\% of all pregnancies are complicated by $\mathrm{PIH}^{(6)}$ while in South Africa, $\mathrm{PIH}$ is found in $18 \%$ of all pregnancies and Eclampsia in $0.94-1.8 \%$ Cases(7). Maternal mortality was found in $10-15 \%$ and perinatal mortality \& morbidity in $15-25 \%$ in one study. ${ }^{(8)}$ According to Crowther study incidence of PIH in booked cases were $19.7 \%$ and unbooked cases were 22.2\%.(9) Kayode 0 et al. showed PIH prevalance1.8 to16.7\% in developing countries.(10) Nusrat Nihal et al. showed prevalence of PIH $10 \%$ in their study done at Hyderaba(d!) Perinatal mortality was 230/1000 in Hyderabad study, whereas it was 107/1000 in our study (unbooked cases). No perinatal mortality was seen in our booked case whereas it was 40/1000 in Hyderabad study. Youcesoy G et al. in 2005 showed perinatal mortality144/1000 (booked and unbooked cases) which is similar to our study.(12)

CONCLUSION: Pregnancy induced hypertension is not a totally preventable disease but the maternal and foetal Complication due to PIH can be halted at mild stage by quality antenatal care with good outcome. 


\section{REFERENCES:}

1. Kayode O. Osungbade, Olusimbo K. Ige. Public Health Perspectives of Preeclampsia in Developing Countries: Implication for Health System Strengthening. Journal of Pregnancy 2011;10:1155.

2. Muhammad Obaid Ur Rehman, Salah-Ud-Din, Muhammad Aslam Siddiqui, Sarwat Rehman. Incidence Of Women Having Pregnancy Induced Hypertension In Karachi. Pak. Jour. of Pharmacology 2003; 20:5-8.

3. Noreen Murray, Caroline SE Homer, Gregory K Davis, Julie Curtis, George Mangos, Mark A Brown. The clinical utility of routine urinalysis in pregnancy: a prospective study. MJA 2002;177:477-80

4. Bailey, David J.; Walton, Stuart M. Routine Investigations Might be Useful in Preeclampsia, But Not in Gestational Hypertension. Obstetrical\& Gynecological Survey. Wolters Kluwer Health Logo.

5. Villar J, Carroli G, Wojdyla D, Abalos E. Preeclampsia, gestational hypertension and intrauterine growth restriction, related or independent conditions? Am J Obstet Gynecol. 2006;194:921-31.

6. Cande V, Ananth John C, Smulian, William E, Scorza. The impact care on post neonatal deaths in the presence and absence of antenatal high-risk conditions. American Journal of Obstetrics \& Gynecology 2002;187:1258-62.

7. Yücesoy G, Ozkan S, Bodur H, Tan T, Calişkan E, Vural B et al.Maternal and perinatal outcome in pregnancies complicated with hypertensive disorder of pregnancy: a seven year experience of a tertiary care center. Arch Gynecol Obstet. 2005;273:43-9.

8. GO Igberase, PN Ebeigbe. Eclampsia: ten-years of experience in a rural tertiary hospital in the Niger delta. Nigeria Journal of Obstetrics \& Gynaecology 2006; 26: 414-7.

9. Crowther CA, Hiller JE, Pridmore B, Bryce R, Duggan P, Hague WM et al. Calcium Supplementation In Nulliparous Women For The Prevention Of Pregnancy-Induced Hypertension, Preeclampsia And Preterm Birth: An Australian Randomized trial.Australian and New Zealand Journal of Obstetrics and Gynaecology 1999;39:12-18.

10. Kayode 0, Osungbade, Olusimbo K I. Public Health Perspectives of Preeclampsia in Developing Countries: Implication for Health System Strengthening. Journal of Pregnancy Volume 2011;10:1155.

11. Pallab Rudra, Sonela Basak, Dilip Patil, MY Latoo. Recent Advances In Management Of Pre-Eclampsia. BJMP 2011;4:433.

12. Yücesoy G, Ozkan S, Bodur H, Tan T, Calişkan E, Vural B et al. Maternal and perinatal outcome in pregnancies complicated with hypertensive disorder of pregnancy: a seven year experience of a tertiary care center. Arch Gynecol Obstet. 2005; 273:43-9.

\begin{tabular}{|l|l|l|}
\hline Foetal outcome & Booked Cases & Unbooked Cases \\
\hline Preterm & NIL & 7 \\
Term with average weight & 16 & 10 \\
Intrauterine Growth Retardation & NIL & 8 \\
Intrauterine Death & NIL & 3 \\
\hline
\end{tabular}

